\title{
KOMPARASI PENCAHAYAAN BOOTH DENGAN METODE PERHITUNGAN MANUAL DAN SIMULASI RELUX DESKTOP 2020.2.3.0
}

\author{
Tri Susetyo Andadari ${ }^{1}$, LMF Purwanto ${ }^{2}$, Prasasto Satwiko ${ }^{3}$, Ridwan Sanjaya ${ }^{4}$ \\ 1,2,3,4 Program Studi Doktor Arsitektur Konsentrasi Arsitektur Digital Universitas Katolik \\ Soegijapranata Semarang
}

Penulis korespondensi: Tri Susetyo Andadari, andadaritri@ gmail.com

Naskah diajukan pada: 16 Desember 2020

Naskah revisi akhir diterima pada: 28 Februari 2021

\begin{abstract}
Abstrak
Sistem perhitungan pencahayaan penting untuk mengetahui jumlah dan tipe armatur, tingkat efektifitas kuat penerangan pada bidang kerja, serta untuk mengetahui besarnya pemakaian energi listrik pada suatu ruangan. Sistem perhitungan pencahayaan bisa dilakukan secara manual atau dengan simulasi menggunakan software pencahayaan. Kedua metode tersebut, menjadi alternatif pilihan bagi arsitek dalam mendapatkan formula pencahayaan buatan untuk desainnya. Namun permasalahannya adalah bagaimanakah perbandingan ketepatan kedua metode tersebut? Bagaimanakah hasil kedua metode tersebut terhadap standar yang berlaku? Dan bagaimanakah kualitas hasil perhitungan kedua metode tersebut? Untuk itulah, penelitian ini berusaha membandingkan metode perhitungan pencahayaan secara manual dan secara simulasi agar hasilnya bisa digunakan sebagai acuan arsitek dalam menentukan sistem perhitungan pencahayaan yang tepat pada desainnya. Penelitian ini merupakan penelitian eksperimental, dengan metode komparatif dan menggunakan booth sebagai media uji. Software simulasi yang dipilih adalah Relux Desktop versi 2020.2.3.0, dengan pertimbangan sudah lama release, mudah pengoperasionalannya dan banyak digunakan oleh praktisi. Hasil akhir menunjukkan bahwa luaran perhitungan sistem pencahayaan secara simulasi (1) lebih akurat dengan deviasi maximal 4\%, (2) rerata besar kuat penerangan pada bidang kerja dan pemakaian energi listrik lebih rendah terhadap standar yang berlaku dan (3) kualitas luaran lebih lengkap berupa kalkulasi, gambar perspektif sebaran cahaya dan gambar kontur sebaran pencahayaan sesuai titik lampu.
\end{abstract}

Kata-kata Kunci: Perhitungan Pencahayaan, Simulasi Pencahayaan, Relux Desktop

\section{BOOTH LIGHTING COMPARISON WITH MANUAL AND RELUX DESKTOP 2020.2.3.0 SIMULATION CALCULATION METHODS}

\begin{abstract}
The lighting calculation system is essential to determine the number and type of armature, light strength effectiveness, and electrical energy consumption. The lighting calculation system can be done manually or with simulation software. Both methods are alternative architects to obtain artificial lighting formulas. The problem is how to compare the accuracy of the two methods? How do the results of the two methods against the prevailing standards? And how is the quality of the results of the two methods? This study seeks to compare manual and simulation lighting calculation
\end{abstract}


methods so that the results can be used as a reference for architects in determining the appropriate lighting calculation system. This research is an experimental study, with a comparative method and using a booth as a medium. The simulation software uses Relux Desktop version 2020.2.3.0, because it has been released for a long time, is easy to operate, and is widely used by architects. The final results show that the simulation output of the lighting system is (1) more accurate with a maximum deviation of 4\%, (2) the average light strength in the work area, and the use of electrical energy is lower than the prevailing standards and (3) the quality of the output is more complete in the form of calculations, perspective drawing of light distribution and contour drawing of lighting distribution according to the position of the light points.

\section{Keywords: Lighting Calculation, Lighting Simulation, Relux Desktop}

\section{Pendahuluan}

Lechner mengemukakan bahwa terdapat 3 faktor yang mempengaruhi kenyamanan visual pengguna dalam melakukan aktivitas yaitu kegiatan, kondisi pencahayaan, dan pengamat (Lechner dalam Amalia \& Citraningrum, 2018). Sedangkan Hirning, mengungkapkan bahwa faktor utama dalam kenyamanan visual adalah menghindari beberapa jenis silau yaitu ketidakmampuan, ketidaknyamanan, dan silau yang menyilaukan (Hirning, 2014). Terkait peran pencahayaan, Dehoff mengatakan "Pencahayaan dapat memainkan peran penting dalam meningkatkan nilai total bangunan untuk aktivitas dan kesehatan, sejauh dianggap setara dengan efisiensi energi" (Dehoff, 2014) (Dehoff, 2012). Menurut Habel dan Žák tujuan dari desain pencahayaan adalah untuk menciptakan kondisi pencahayaan yang sesuai untuk aktivitas visual tertentu (Habel \& Žák, 2011). Oleh karena itu, perencanaan pencahayaan memegang peranan penting bagi keberhasilan sistem pencahayaan yang baik dan ekonomis.

Duff menyatakan bahwa praktik desain pencahayaan diatur oleh berbagai dokumen panduan dan standar, dimana masing-masing merekomendasikan sejumlah kriteria yang harus diterapkan untuk memastikan keamanan dan kepuasan penghuni gedung (Duff, 2015). Untuk Negara Indonesia, sistem pencahayaan buatan didasarkan atas standar SNI tata cara perancangan sistem pencahayaan buatan pada bangunan gedung, agar diperoleh sistem pencahayaan buatan yang sesuai dengan syarat kesehatan, kenyamanan, keamanan dan memenuhi ketentuan yang berlaku untuk bangunan gedung (Standar Nasional Indonesia, 2001).

Metode perhitungan pencahayaan bisa dilakukan dengan cara manual (perhitungan, grafis dan diagram) atau yang lebih mutakhir adalah dengan simulasi digital menggunakan software tertentu. Metode perhitungan pencahayaan secara manual prinsipnya didasarkan pada hukum-hukum fisika cahaya (Ningsar \& Sangkertadi, 2013). Prosedur dan rumus yang dipakai pada perhitungan manual mengacu pada prosedur menurut Standar Nasional Indonesia SNI-03-6575-2001 (Standar Nasional Indonesia, 2001) dan referensi pustaka dari Szokolay (Szokolay dalam Ningsar \& Sangkertadi, 2013). Menurut Mandala, meskipun perhitungan grafis manual cukup akurat dalam memprediksi kuantitas cahaya, namun kompleksitas yang tinggi menimbulkan kendala berupa lamanya waktu pengerjaan dan akurasi hasil perhitungan manual (Ariani Mandala , Amirani Ritva S, 2016).

Terkait teknologi pencahayaan, Kralikova mengemukakan "A lighting technology is not only one of considerably developing industries of economy, but also one of the most progressive developing branches of the science and technology. New materials and technology, a penetration of thin layers, microelectronics and computer technology into the lighting technology enormously promote its development" (Kralikova et al., 2015). Teknologi simulasi pencahayaan, walaupun dapat digunakan untuk menghitung berbagai kategori metrik kinerja pencahayaan, namun, metrik ini tidak dengan mudah dan transparan diterjemahkan ke dalam suatu value tertentu (Davoodi, 2016). Menurut Bossel terdapat kelebihan dan kekurangan pengunaan perangkat simulasi. Kelebihannya 
adalah tidak ada ancaman bagi sistem; hasil diperoleh dengan cepat; investigasi dapat mencakup jangkauan yang lebih luas; jalur pengembangan alternatif dapat dipelajari dan dibandingkan; dan biaya jauh lebih kecil. Sedangkan kekurangannya adalah ada ketidakpastian tentang apakah model tersebut menggambarkan perilaku sistem dengan benar di semua aspeknya (Bossel, 2007). Fungsi lain dari simulasi adalah sebagai sarana menyiasati terjadinya konflik kriteria desain, seperti konsumsi energi minimum terhadap kenyamanan visual maksimum, yang meningkatkan kebutuhan pengoptimalan (Fesanghary et al., 2012) (Hamdy et al., 2011). Salah satu jenis software pencahayaan yang umum digunakan di dunia kerja adalah Relux Desktop versi 2020.2.3.0, yang mempunyai kemampuan melakukan kalkulasi pencahayaan untuk instalasi di dalam dan luar ruangan termasuk jalan dan terowongan (Bouroussis et al., 2019). Pemilihan software Relux Desktop versi 2020.2.3.0 dalam penelitian ini, didasarkan pada pertimbangan bahwa software tersebut merupakan software pencahayaan keluaran Autodesk.Inc yang sudah cukup lama release, yang cukup mudah pengoperasionalannya, compatible dengan software produk pencahayaan lainnya dan cukup familiar dikalangan praktisi arsitek.

Adanya berbagai macam metode perhitungan diatas, memberikan pilihan bagi arsitek dalam mendapatkan formula pencahayaan buatan untuk desain yang dibuatnya. Namun yang perlu dipertanyakan adalah bagaimanakah perbandingan ketepatan hasil perhitungan kedua metode tersebut? Bagaimanakah hasil kedua metode tersebut terhadap standar yang berlaku? Dan bagaimakah kualitas hasil perhitungan kedua metode tersebut? Berdasarkan rumusan masalah tersebut, maka perlu kiranya satu penelitian untuk membandingkan metode perhitungan pencahayaan secara manual dengan metode pencahayaan menggunakan simulasi digital dengan software Relux Desktop versi 2020.2.3.0, agar hasilnya bisa digunakan sebagai acuan arsitek dalam menentukan sistem perhitungan pencahayaan yang dapat diterapkan pada desainnya.

Dalam penelitian ini, digunakan booth interior sebagai media observasi perbandingan, dimana sistem pencahayaannya menggunakan sistem pencahayaan merata, dengan pertimbangan bahwa dalam booth interior perlu adanya kuat penerangan yang merata, karena pengunjung booth akan melakukan pergerakan pada semua ruang untuk melakukan pengamatan terhadap seluruh isi booth. Booth merupakan sebuah ruang yang berada di dalam ruang, yang digunakan untuk pameran dengan waktu tertentu dan pada area yang terbatas (Widodo et al., 2016). Karena sifatnya sebagai ruang pamer, maka pencahayaan pada booth menjadi unsur penting selain untuk memberikan point of intererest pada barang yang akan di pamerkan, juga mampu memberikan efek psikologis pada pengunjung. Menurut Pegler, "pameran adalah sebuah tampilan yang menstimulasi dan menguak ketertarikan konsumen terhadap produk, ide, maupun sebuah organisasi dimana sebuah pameran itu sendiri diatur dan diorganisir untuk menyediakan kesenangan yang menjawab kebutuhan pengunjung dan pencerahan ide bagi beberapa pengunjung khusus, sekaligus bisa digunakan untuk mengedukasi, mengiklan dan menyebarluaskan produk yang ditampilkan dari pameran tersebut" (Pegler, 2012).

\section{Metode}

Penelitian ini termasuk dalam penelitian eksperimen, dimana menurut Davoodi penelitian ekperiman adalah sarana utama untuk memahami persepsi cahaya (Davoodi, 2016). Hal mendasar yang diangkat dalam penelitian ini adalah terkait dengan flux cahaya, dimana flux cahaya adalah jumlah cahaya yang dipancarkan oleh sumber cahaya, dan Choudhury menyatakan "Luminous flux, or luminous power, is the measure of the perceived power of light" (Choudhury, 2014).

Secara garis besar metode penelitian dibagi dalam 3 tahapan, yaitu (1) perhitungan pencahayaan secara manual, (2) perhitungan pencahayaan dengan software Relux Desktop versi 2020.2.3.0 dan (3) melakukan komparansi hasil perhitungan pencahayaan secara manual dengan software Relux Desktop versi 2020.2.3.0, berdasarkan Standar Nasional Indonesia.

Perhitungan pencahayaan secara manual menggunakan asumsi sistem penerangan merata. Sumber data empiris primer didapat dari website resmi produsen lampu merk Philips untuk 
mendapatkan data produk yang digunakan untuk perhitungan, sedangkan data empiris sekunder didapat dari Standar Nasional Indonesia SNI-03-6575-2001 tentang tata cara perancangan sistem pencahayaan buatan pada bangunan gedung, (Standar Nasional Indonesia, 2001), untuk mendapatkan besaran angka standar yang berlaku. Tata urutan yang digunakan dalam perhitungan pencahayaan secara manual didasarkan pada perhitungan Fluks cahaya $(\Phi)$, dimana menurut Poling didefinisikan sebagai fungsi intensitas pencahayaan dalam arah tertentu (Poling, 2018), dengan rumus sebagai berikut:

1. Penentuan Besaran Indeks Ruang (IR)

$$
I R=\frac{(l \times w)}{h_{e f f}(l+w)}
$$

1 adalah Panjang ruangan $(\mathrm{m}), \mathrm{w}$ adalah lebar ruangan $(\mathrm{m}), \mathrm{h}_{\text {eff }}$ adalah tinggi lampu terhadap bidang kerja $(\mathrm{m})$

2. Penentuan Besaran flux cahaya (lumen) teoretis pada bidang kerja ( $\Phi r)$

$$
\phi_{r}=E \times A
$$

E adalah kuat penerangan (lux) pada bidang kerja, dan A adalah luas lantai $\left(\mathrm{m}^{2}\right)$

3. Penentuan Besaran flux cahaya (lumen) dari Rencana (desain) ( $\Phi D)$

$$
\phi_{D}=\frac{\Phi_{r}}{M F \times U F}
$$

$\mathrm{UF}=$ Utilization Faktor yaitu faktor penggunaan, $\mathrm{MF}=$ Manitenance Factor yaitu faktor pemeliharaan produk. Besaran angka UF diambil dari standar pengukuran cahaya, dan besaran MF diambil dari katalog produk lampu dan armature yang digunakan.

4. Penentuan Perhitungan jumlah titik lampu $(\mathrm{N})$

$$
N=\frac{\Phi_{D}}{\Phi_{L}}
$$

Metode perhitungan pencahayaan dengan sistem simulasi pada penelitian ini menggunakan software Relux Desktop versi 2020.2.3.0. Sumber data empiris primer dan sekunder yang digunakan untuk metode simulasi dan perhitungan manual adalah sama seperti dikemukakan diatas. Adapun Langkah-langkah dalam perhitungan menggunakan sistem simulasi secara garis besar adalah (1) Penggambaran lay ot dan 3d ruangan, (2) input banyaknya lampu, jenis lampu dan besaran daya sesuai dengan data yang digunakan pada sistem perhitungan pencahayaan secara manual, (3) melakukan analisis rendering pada software, (4) output berupa hasil perhitungan, gambar visual, sebaran/contour cahaya.

Langkah selanjutnya adalah menganalisis luaran hasil perhitungan pencahayaan baik secara manual maupun menggunakan simulasi software Relux Desktop versi 2020.2.3.0. Cara melakukan komparansi adalah dengan membaca besaran hasil perhitungan secara manual dan secara simulasi dengan merujuk pada standar tingkat pencahayaan menurut Standar Nasional Indonesia SNI-036575-2001, untuk mengetahui tingkat penyimpangan yang didapat (Ningsar \& Sangkertadi, 2013). Semakin tinggi tingkat penyimpangan terhadap Standar Nasional Indonesia SNI-03-6575-2001, maka hasil perhitungan pencahayaan tersebut menunjukkan tingkat ketidak-efektifan dan ketidakekonomisan yang semakin tinggi (Ningsar \& Sangkertadi, 2013). Cara pengkoreksiannya bisa dilakukan dengan menambah jumlah lampu atau mengganti jenis lampu atau mengganti besaran daya lampu, sehingga didapatkan angka yang memenuhi yang paling mendekati Standar Nasional Indonesia SNI-03-6575-2001. Realitasnya, menurut Yu metode komparansi hasil simulasi pencahayaan Relux dilakukan dengan membandingkan hasil simulasi yang didapat dengan maximal penyimpangan sebesar 20\% terhadap realitas lapangan (Yu et al., 2014). 
Adapun booth yang dijadikan studi kasus adalah booth untuk display produk interior dengan ukuran ruang $15 \mathrm{~m}$ x $6 \mathrm{~m}$, dengan ketinggian 3 meter. Materi dinding dan plafon merupakan kayu dengan finishing warna terang yang diasumsikan nilai reflektansinya adalah sebesar 0,7 dan material lantai adalah karpet dengan warna coklat muda yang dianggap tidak memantulkan cahaya. Standar tingkat pencahayaan minimal untuk ruang pamer adalah sebesar 500 lux sesuai Standar Nasional Indonesia (SNI 03-6575-2001). Dan daya lampu maksimum sesuai standar konservasi energi menurut Standar Nasional Indonesia (SNI 03-6575-2001) untuk tipe ruang pamer disetarakan dengan ruang auditorium sebesar $25 \mathrm{~W} / \mathrm{m}^{2}$.

\section{Hasil dan Pembahasan}

\section{Hasil Perhitungan Pencahayaan Booth Secara Manual}

Hasil perhitungan pencahayaan dengan cara perhitungan manual dilakukan berdasarkan rumusrumus diatas, seperti terlihat pada tabel dibawah ini.

Tabel 1. Tabel Hasil Perhitungan Manual

\begin{tabular}{lcc}
\hline \multicolumn{1}{c}{ Item Perhitungan } & Hasil & Satuan \\
\hline Luas Ruangan & 90 & $\mathrm{~m} 2$ \\
\hline Kuat Penerangan Minimal Pada Bidang Kerja & 500 & Lux \\
\hline Room Indeks & 1.42 & \\
\hline Flux Teoretis Pada Bidang Kerja & 45000 & lumen \\
\hline UF & 0.9 & $\mathrm{~W}$ \\
\hline MF & 0.8 & lumen \\
\hline Daya setiap Lampu & 34.5 & lumen \\
\hline Lumen Setiap Lampu & 3900 & $\mathrm{Buah}$ \\
\hline Lumen Desain & 62500 & $\mathrm{w} / \mathrm{m}^{2}$ \\
\hline Jumlah Titik Lampu & 16 & \\
\hline Kontrol Pemakaian Energi Listrik & 6.1431 &
\end{tabular}

Sumber: Analisis Pribadi, 2020

Pada tabel diatas terlihat bahwa dengan luasan area booth sebesar $90 \mathrm{~m}^{2}$, dibutuhkan 16 titik lampu jenis armatur downlight merk Philip Luxspace recessed dengan seri DN570B_TWH-4000, dimana besaran daya per lampu adalah 34.5watt, luminous efficacy sebesar $113.04 \mathrm{~lm} / \mathrm{watt}$ dan dengan system light lux per lampu sebesar 3900 lumen. Sehingga secara keseluruhan ruang, kontrol pemakaian energi listrik untuk pencahayaan adalah sebesar $6.1431 \mathrm{watt} / \mathrm{m} 2$. Angka ini masih lebih rendah dari nilai standar yang direkomendasikan oleh SNI untuk ruang pamer yang disetarakan dengan ruang auditorium yaitu $25 \mathrm{watt} / \mathrm{m}^{2}$.

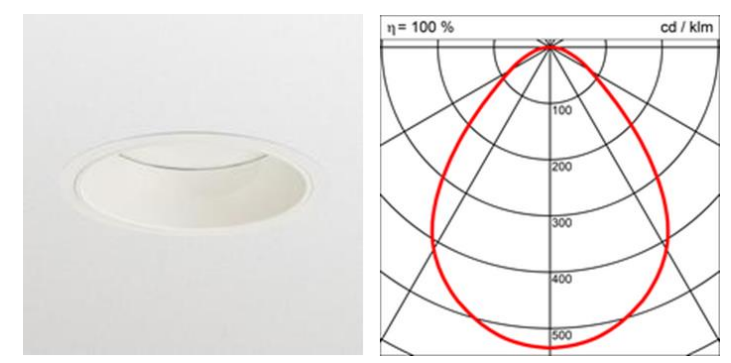

Gambar 1. Tampilan Dan Light Distribution Curve Armature Downlight Philip Luxspace Recessed Seri DN570B_TWH-4000

Sumber: Philips, 2013 
Pemilihan tipe armatur downlight dilakukan karena pertimbangan untuk menghindari resiko silau pada pengguna. Selain itu karakteristik armature downlight dapat mengarahkan berkas sinar cahaya secara terfokus pada bidang lingkaran dibawahnya, seperti ditunjukkan pada gambar 2 dan 3 , dimana konsep distribusi pancaran sinar cahaya berpola "distribusi kerucut" terhadap bidang kerjanya pada tatanan potongan dan konsep distribusi pancaran sinar cahaya berpola "distribusi lingkaran" pada tataran denah.

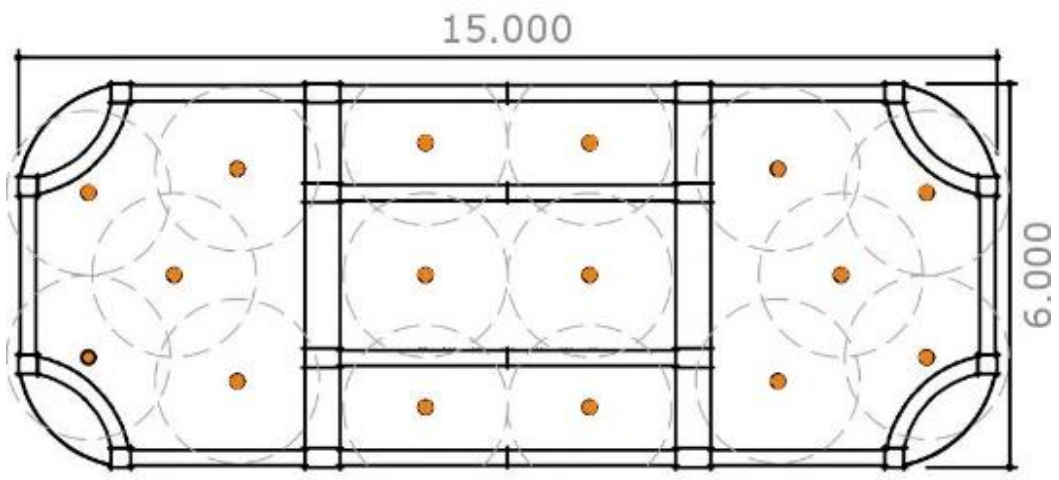

Gambar 2. Denah Posisi Lampu Dan Distribuasi Cahaya Berpola Lingkaran Sumber: Analisa Pribadi, 2020

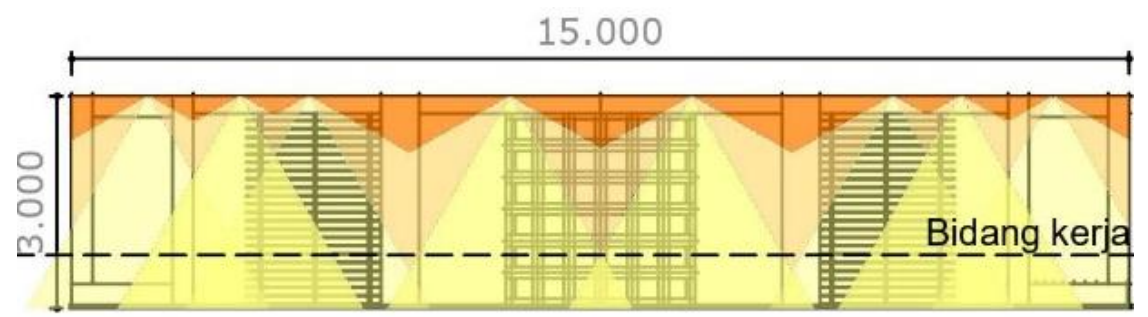

Gambar 3. Potongan Dan Distribusi Sinar Cahaya Berpola Kerucut Sumber: Analisa Pribadi, 2020
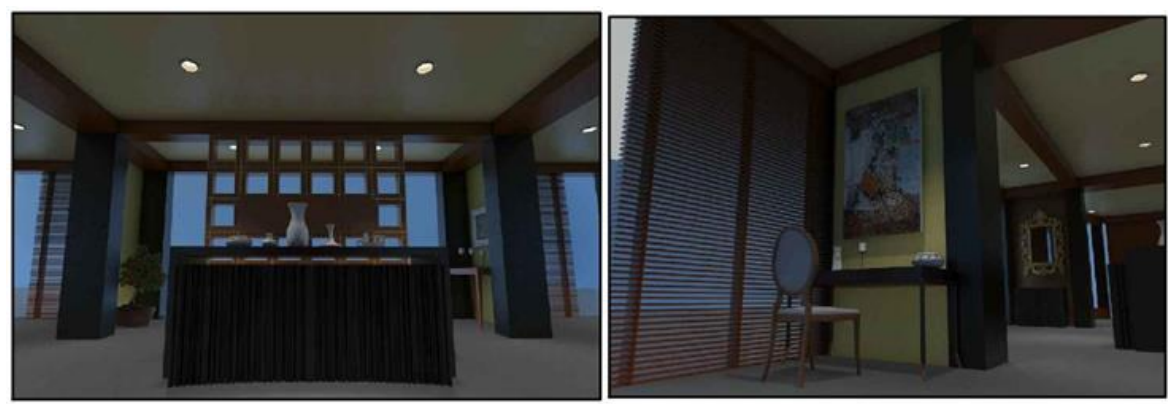

Gambar 4. Perspektif Booth

Sumber: Analisa Pribadi, 2020

\section{Hasil Perhitungan Pencahayaan Booth Dengan Simulasi Software Relux Desktop versi 2020.2.3.0}

Dengan jenis dan penempatan titik lampu yang sesuai dengan perhitungan manual, dilakukan simulasi dengan menggunakan software Relux Desktop versi 2020.2.3.0. Hasil kontur kuat penerangan (lux) pada bidang kerja, terlihat pada gambar 5, dimana besaran sebaran illuminance mulai pada range 15 sampai dengan 500 lux, dengan rata-ratanya adalah 480 lux. Angka ini dibawah standar tingkat pencahayaan berdasarkan Standar Nasional Indonesia (SNI 03-6575-2001) dimana angka minimal untuk ruang pamer yaitu sebesar 500 lux. 


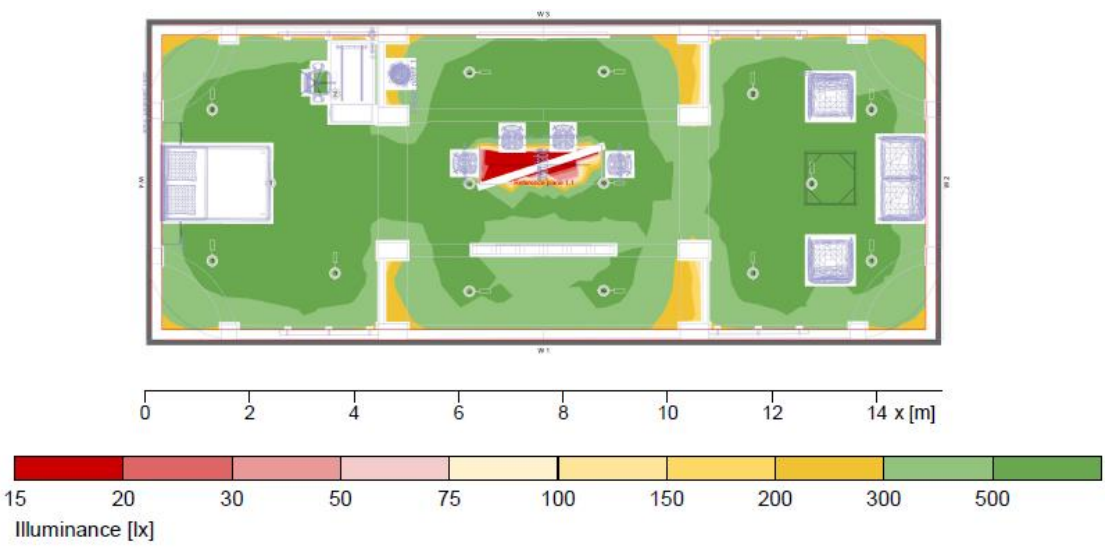

Gambar 5. Kontur Kuat Penerangan (Lux) Pada Bidang Kerja Sumber: Hasil Simulasi Pribadi, 2020

Hasil kalkulasi system pencahayaan Booth dengan software Relux Desktop versi 2020.2.3.0 seperti terlihat pada gambar 6 dibawah ini. Dimana Total Luminous flux untuk semua lampu adalah sebesar 62.400 lumen, dengan total power sebesar 552-watt dan total power per area adalah sebesar $6.13 \mathrm{watt} / \mathrm{m}^{2}$. Angka ini masih memenuhi standar daya lampu maksimum berdasarkan konservasi energi menurut Standar Nasional Indonesia (SNI 03-6575-2001) untuk tipe ruang pamer yang disetarakan dengan ruang auditorium sebesar $25 \mathrm{~W} / \mathrm{m}^{2}$.

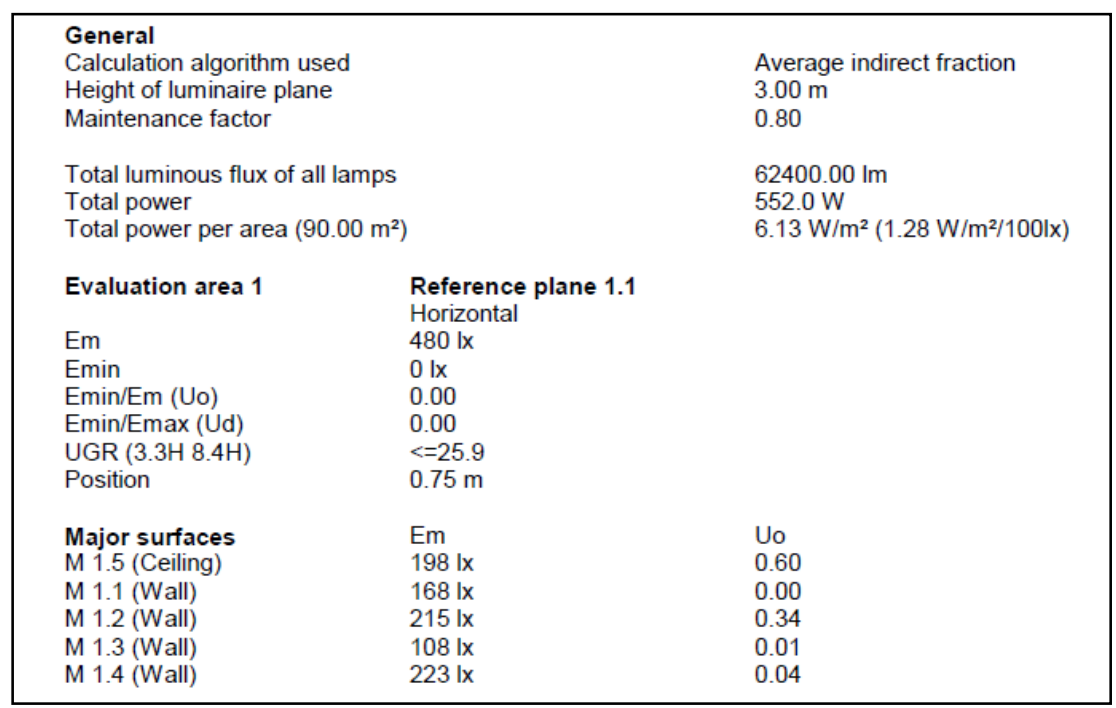

Gambar 6. Hasil Kalkulasi Sistem Pencahayaan Dengan Software Relux Desktop Versi 2020.2.3.0

Sumber: Hasil Simulasi Pribadi, 2020

Posisi lampu dan sebaran cahaya hasil simulasi dengan software Relux Desktop versi 2020.2.3.0 bisa dilihat pada gambar 7 dibawah ini. 


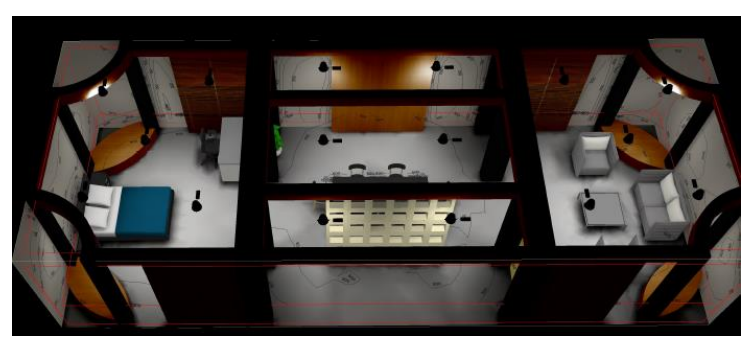

Gambar 7. Perspektif Booth Hasil Simulasi Software Relux Desktop versi 2020.2.3.0

Sumber: Hasil Simulasi Pribadi, 2020

\section{Perbandingan Hasil Perhitungan Pencahayaan}

Perbandingan hasil perhitungan pencahayaan dengan cara manual dan simulasi menggunakan software Relux Desktop versi 2020.2.3.0, ditampilkan dalam Tabel 2 dibawah ini.

Tabel 2. Perbandingan Hasil Kalkulasi Sistem Pencahayaan

\begin{tabular}{|c|c|c|c|c|}
\hline \multirow[t]{2}{*}{ Item Perhitungan } & \multicolumn{2}{|c|}{$\begin{array}{c}\text { Perhitungan } \\
\text { Manual }\end{array}$} & \multicolumn{2}{|c|}{ Relux Desktop versi 2020.2.3.0 } \\
\hline & Hasil & Satuan & Hasil & Satuan \\
\hline Luas Ruangan & 90 & $\mathrm{~m} 2$ & 90 & $\mathrm{~m} 2$ \\
\hline $\begin{array}{l}\text { Kuat Penerangan Minimal Bid } \\
\text { Kerja }\end{array}$ & 500 & Lux & 480 & $\operatorname{lux}$ \\
\hline Room Indeks & 1.42 & & 1.42 & \\
\hline Flux Teoretis Pada Bidang Kerja & 45000 & lumen & 43200 & lumen \\
\hline UF & 0.9 & & 0.9 & \\
\hline MF & 0.8 & & 0.8 & \\
\hline Daya setiap Lampu & 34.5 & $\mathrm{~W}$ & 34.5 & $\mathrm{w}$ \\
\hline Lumen Setiap Lampu & 3900 & lumen & 3900 & lumen \\
\hline Lumen Desain & 62500 & lumen & 62400 & lumen \\
\hline Jumlah Titik Lampu & 16 & Buah & 16.00 & buah \\
\hline Kontrol Pemakaian Energi Listrik & 6.14316 & $\mathrm{w} / \mathrm{m} 2$ & 6.13 & $\mathrm{w} / \mathrm{m} 2$ \\
\hline
\end{tabular}

Sumber: Hasil Simulasi Pribadi, 2020

Dari tabel perbandingan hasil kalukasi diatas, bisa dilihat bahwa besaran nilai sistem pencahayaan hasil perhitungan manual dengan simulasi menggunakan software Relux Desktop versi 2020.2.3.0, tidak berbeda signifikan. Namun yang perlu dicermati adalah bahwa rata-rata kuat penerangan minimal bidang kerja dengan menggunakan software Relux Desktop versi 2020.2.3.0, hanya sebesar 480 lux. Ini artinya adalah bahwa hasil simulasi perhitungan pencahayaan tersebut tidak memenuhi standar yang berlaku yaitu Standar Nasional Indonesia (SNI 03-6575-2001) dimana angka minimal untuk ruang pamer yaitu sebesar 500 lux. Untuk itu perlu dilakukan koreksi terhadap perhitungan system pencahayaan manual dengan melakukan penambahan titik lampu. Dibawah ini adalah salah satu contoh penambahan jenis lampu dan armatur yang sudah disimulasikan dalam software Relux Desktop versi 2020.2.3.0.

Hasil koreksi kontur kuat penerangan (lux) pada bidang kerja dengan menggunakan software Relux Desktop versi 2020.2.3.0, terlihat pada gambar 8, dimana besaran sebaran illuminance mulai pada range 75 sampai dengan 500 lux, dengan rata-ratanya adalah 500 lux. Angka ini sesuai dengan standar tingkat pencahayaan berdasarkan Standar Nasional Indonesia (SNI 03-6575-2001) dimana angka minimal untuk ruang pamer yaitu sebesar 500 lux. 


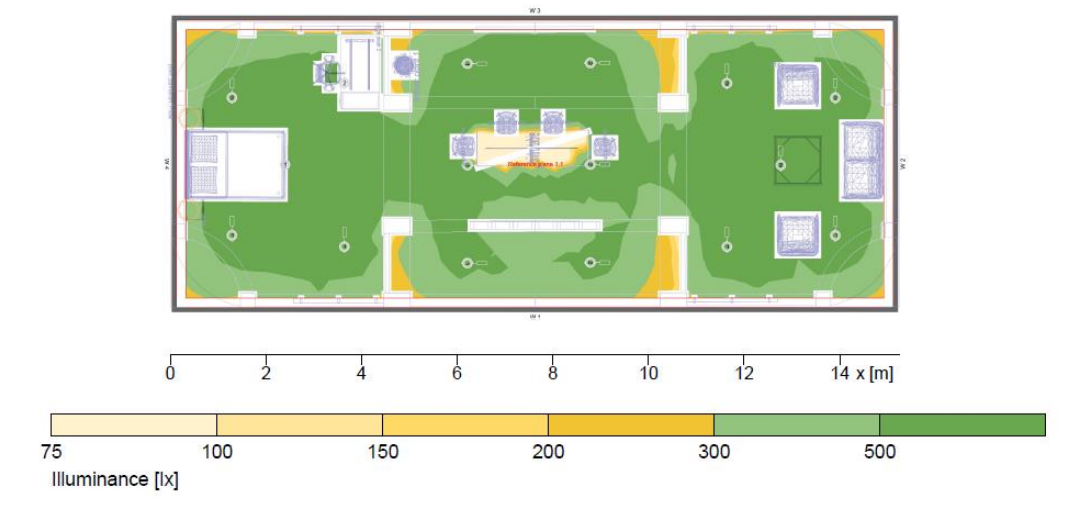

Gambar 8. Hasil Koreksi Kontur Kuat Penerangan (Lux) Pada Bidang Kerja

Sumber: Hasil Simulasi Pribadi, 2020

Hasil koreksi kalkulasi system pencahayaan Booth dengan software Relux Desktop versi 2020.2.3.0 seperti terlihat pada gambar 9 dibawah ini. Dimana Total Luminous flux untuk semua lampu adalah sebesar 66.800 lumen, dengan total power sebesar 590-watt dan total power per area adalah sebesar $6.56 \mathrm{watt} / \mathrm{m}^{2}$. Angka ini masih memenuhi standar daya lampu maksimum berdasarkan konservasi energi menurut Standar Nasional Indonesia (SNI 03-6575-2001) untuk tipe ruang pamer yang disetarakan dengan ruang auditorium sebesar $25 \mathrm{~W} / \mathrm{m}^{2}$.

\begin{tabular}{|c|c|c|}
\hline \multicolumn{2}{|c|}{$\begin{array}{l}\text { General } \\
\text { Calculation algorithm used } \\
\text { Maintenance factor }\end{array}$} & $\begin{array}{l}\text { Average indirect fraction } \\
0.80\end{array}$ \\
\hline \multicolumn{2}{|c|}{$\begin{array}{l}\text { Total luminous flux of all lamps } \\
\text { Total power } \\
\text { Total power per area }\left(90.00 \mathrm{~m}^{2}\right)\end{array}$} & $\begin{array}{l}66800.00 \mathrm{Im} \\
590.0 \mathrm{~W} \\
6.56 \mathrm{~W} / \mathrm{m}^{2}\left(1.31 \mathrm{~W} / \mathrm{m}^{2} / 100 \mathrm{Ix}\right)\end{array}$ \\
\hline $\begin{array}{l}\text { Evaluation area } 1 \\
\text { Em } \\
\text { Emin } \\
\text { Emin/Em (Uo) } \\
\text { Emin/Emax (Ud) } \\
\text { Position }\end{array}$ & $\begin{array}{l}\text { Reference plane } 1.1 \\
\text { Horizontal } \\
500 \mathrm{~lx} \\
0 \mathrm{Ix} \\
0.00 \\
0.00 \\
0.75 \mathrm{~m}\end{array}$ & \\
\hline $\begin{array}{l}\text { Major surfaces } \\
\text { M 1.5 (Ceiling) } \\
\text { M } 1.1 \text { (Wall) } \\
\text { M } 1.2 \text { (Wall) } \\
\text { M 1.3 (Wall) } \\
\text { M 1.4 (Wall) }\end{array}$ & $\begin{array}{l}E m \\
219 \mid x \\
178 \mid x \\
233 \mid x \\
118 \mid x \\
252 \mid x\end{array}$ & $\begin{array}{l}\text { Uo } \\
0.55 \\
0.00 \\
0.33 \\
0.01 \\
0.03\end{array}$ \\
\hline
\end{tabular}

Gambar 9. Hasil Koreksi Kalkulasi Sistem Pencahayaan Dengan Software Relux Desktop Versi 2020.2.3.0

Sumber: Hasil Simulasi Pribadi, 2020

Spesifikasi dan jumlah armature serta jenis lampu yang diterapkan dalam koreksi kalkulasi sistem pencahayaan dengan Software Relux Desktop versi 2020.2.3.0 terdiri dari 2 buah lampu Philips CoreLine Wall-mounted dengan seri WL130V PSU D350_840/WL130V PSU D350, 2 buah lampu Philips TownTune Asymmetric Lyre dengan seri BDP270_740/BDP270 dan 16 buah lampu Philips LuxSpace recessed dengan seri DN570B_TWH-4000/DN570B, seperti terlihat pada gambar 10 dibawah ini. 


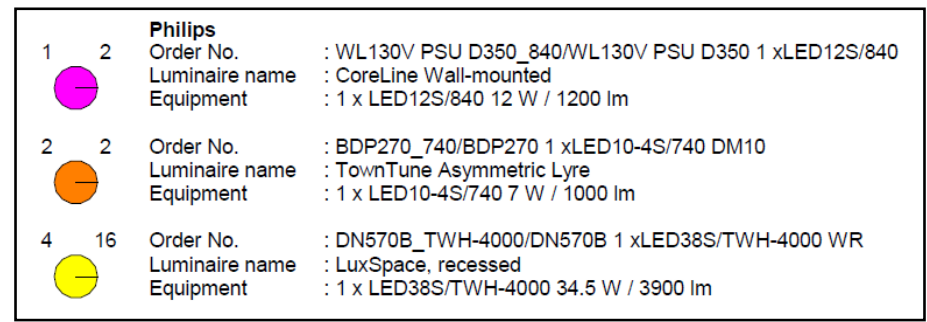

Gambar 10. Spesifikasi, Jumlah Dan Jenis Armature Pada Koreksi Kalkulasi Sistem Pencahayaan Dengan Software Relux Desktop Versi 2020.2.3.0

Sumber: Hasil Simulasi Pribadi, 2020

Posisi lampu dan sebaran cahaya hasil koreksi simulasi dengan software Relux Desktop versi 2020.2.3.0 Bisa dilihat pada gambar 11 dibawah ini.

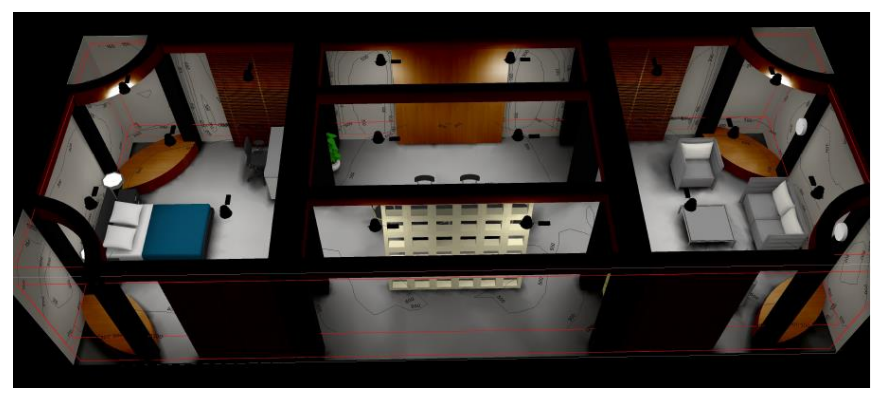

Gambar 11. Perspektif Booth Hasil Koreksi Simulasi Software Relux Desktop

Versi 2020.2.3.0

Sumber: Hasil Simulasi Pribadi, 2020

\section{Kesimpulan dan Rekomendasi}

Dari analisa komparansi perhitungan sitem pencahayaan secara manual dan simulasi menggunakan software diatas, dapat diambil kesimpulan:

1. Perbandingan hasil perhitungan sistem pencahayaan baik secara manual dan cara simulasi tidak berbeda signifikan. Persentase perbedaan maximal nominal hasil perhitungan secara manual dan secara simulasi, sebesar $4 \%$ (lihat tabel 2), dimana tingkat akurasi perhitungan secara simulasi lebih akurat.

2. Besaran rata-rata kuat penerangan minimal bidang kerja, Flux Teoretis pada bidang kerja, Lumen Desain dan Kontrol Pemakaian Energi Listrik hasil perhitungan secara simulasi lebih rendah dari hasil perhitungan secara manual sehingga tidak memenuhi standar tingkat pencahayaan yang disyaratkan dan perlu dilakukan adjustment.

3. Terdapat perbedaan yang signifikan antara kualitas luaran hasil perhitungan manual dengan kualitas luaran hasil perhitungan dengan simulasi software. Disamping hasil kalulasi sistem pencahayaan yang lebih akurat, lengkap dan cepat, output simulasi software dapat menampilkan gambar perspektif persebaran cahaya pada area yang diteliti, yang mendekati realitanya, serta gambar kontur sebaran pencahayaan sesuai posisi titik lampu.

Rekomendasi atas hasil kesimpulan pada penelitian ini adalah:

1. Disarankan bagi desainer lighting untuk menggunakan sistem perhitungan pencahayaan dengan software simulasi pencahayaan karena hasil output lebih akurat, cepat dan lengkap mendekati realitas. 
2. Bahwa pada saat ini, jenis dan merk lampu tidak semua ter-incorporate dalam software simulasi, terutama untuk merk lampu lokal, sehingga perlu plug in atau mungkin manually input system untuk produk lampu dan armatur dengan merk lokal supaya bisa compatible dengan software simulasi pencahayaan yang ada.

3. Kedepannya software semacam ini akan sangat membantu desainer lighting tidak hanya terkait dengan sistem perhitungan pencahayaan, juga terkait dengan hasil visualisasinya, namun perlu diperhitungkan agar sistem penggunaaan software simulasi pencahayaan tidak harus dilakukan secara online, untuk mempertimbangkan efisiensi dan sustainability.

\section{Daftar Acuan}

Amalia, Z., \& Citraningrum, A. (2018). Evaluasi Tata Cahaya Pada Ruang Koleksi Perpustakaan Nasional Republik Indonesia di Jakarta. Jurnal Mahasiswa Jurusan Arsitektur Universitas Brawijaya, 6(4).

Ariani Mandala , Amirani Ritva S, R. G. (2016). Perhitungan Manual, Simulasi Maket, Dan Simulasi Digital.

Bossel, H. (2007). Systems and Models. Complexity, Dynamics, Evolution, Sustainability.

Bouroussis, C. A., Nikolaou, D. T., \& Topalis, F. V. (2019). Test report on the validation of Relux Desktop 2019 against CIE 171:2006. Lighting Laboratory, National Technical University of Athens, May. https://doi.org/10.13140/RG.2.2.14488.24320

Choudhury, A. K. R. (2014). 1 - Characteristics of light sources. In A. K. R. Choudhury (Ed.), Principles of Colour and Appearance Measurement (pp. 152). Woodhead Publishing. https://doi.org/https://doi.org/10.1533/97808570 99242.1

Davoodi, A. (2016). Lighting Simulation for a more value-driven building design process. 56. https://sci-hub.do/https://www.divaportal.org/smash/record.jsf?pid=diva2:967485

Dehoff, P. (2012). Lighting Quality and Energy Efficiency is not a Contradiction. Light and Engineering, 20, 34-39.

Dehoff, P. (2014). Measures for a better quality in lighting a journey through recent activities in applications and standards. Light and Engineering, 22, 68-74.

Duff, J. (2015). On a New Method for Interior Lighting Design. Technological University Dublin. https://doi.org/10.21427/D7RS33

Fesanghary, M., Asadi, S., \& Geem, Z. W. (2012). Design of low-emission and energy-efficient residential buildings using a multi-objective optimization algorithm. Building and Environment, 49, 245-250. https://doi.org/https://doi.org/10.1016/j.buildenv. 2011.09.030

Habel, J., \& Žák, P. (2011). Energy performance of lighting systems. Przeglad Elektrotechniczny, 87(4), 20-24.
Hamdy, M., Hasan, A., \& Sirén, K. (2011). Applying a multi-objective optimization approach for Design of low-emission cost-effective dwellings. Building and Environment, 46, 109-123. https://doi.org/10.1016/j.buildenv.2010.07.006

Hirning, M. (2014). The Application of Luminance Mapping to Discomfort Glare: A Modified Glare Index for Green Buildings (p. 148).

Kralikova, R., Andrejiova, M., \& Wessely, E. (2015). Energy saving techniques and strategies for illumination in industry. Procedia Engineering, 100(January), 187-195. https://doi.org/10.1016/j.proeng.2015.01.357

Ningsar, \& Sangkertadi, P. (2013). Perhitungan dan Rancangan Penerangan Buatan pada Ruang Dubbing Suatu Studio Produksi Film (Calculation and Design of Artificial Lighting System of a Dubbing Room). Jurnal Arsitektur DASENG, 2(1), 67-73.

Pegler, M. M. (2012). Visual Merchandising and Display. Fairchild Books.

Philips. (2013). Lighting Catalog Lamp Specification Guide 2013.2163 http://www.usa.lighting.philips.com/pwc_li/us_e n/connect/tools_literature/downloads/sg1002013.pdf

Poling, R. M. (2018). A New Method for Calculating Luminous Flux Using High Dynamic Range Imaging and Its Applications. Faculty of the University of Kansas.

Standar Nasional Indonesia. (2001). Tata cara perancangan sistem pencahayaan buatan pada bangunan gedung. Standar Nasional Indonesia.

Widodo, S., Ardana, I. G. N., Yong, S. De, Studi, P., Interior, D., Petra, U. K., Siwalankerto, J., Knockdown, K. K., \& Lipat, K. (2016). Perancangan Modular Booth Untuk Produk Makanan dan Minuman. Jurnal Intra, 4(2), 515523. file:///D:/interior/Pra TA/Pra TA/Jurnal buat Pra TA/4662-8871-1-SM.pdf

Yu, X., Su, Y., \& Chen, X. (2014). Application of RELUX simulation to investigate energy saving potential from daylighting in a new educational building in UK. Energy and Buildings, 74, 191202.

https://doi.org/https://doi.org/10.1016/j.enbuild.2 014.01 .024 